\title{
Do Margin Requirements Affect Asset Prices?
}

\author{
Bruno C. GiovannetTi \\ GUILHERME B. MARTINS
}

Working PAPER SERIES № 2012-17 


\title{
DEPARTMENT OF ECONOMICS, FEA-USP \\ WORKING PAPER № 2012-17
}

\section{Do Margin Requirements Affect Asset Prices?}

Bruno C. Giovannetti (bcg@usp.br)

Guilherme B. Martins (guilherme.martins@itaubba.com)

\begin{abstract}
:
Some recent theoretical papers show that margin requirements can affect asset prices. Such results are important, for example, to understand the unconventional polices implemented by the Fed during the financial crisis of 2007-2010. However, empirical evidence remains scarce. The present article contributes to filling this gap. It shows that an aggregate margin factor predicts future excess returns of the S\&P 500, and that stocks with high exposures to the ted spread pay on average higher risk-adjusted returns. Both findings are in accordance with the theory that relates margins and prices.
\end{abstract}

Keywords: asset prices, margin requirements, capital constraint

JEL Codes: G01, G10, G12 


\title{
Do Margin Requirements Affect Asset Prices?*
}

\author{
Bruno C. Giovannetti ${ }^{\dagger}$ and Guilherme B. Martins ${ }^{\ddagger}$
}

March 16, 2012

\begin{abstract}
Some recent theoretical papers show that margin requirements can affect asset prices. Such results are important, for example, to understand the unconventional polices implemented by the Fed during the financial crisis of 2007-2010. However, empirical evidence remains scarce. The present article contributes to filling this gap. It shows that (i) an aggregate margin factor predicts future excess returns of the S\&P 500, and that (ii) stocks with higher exposures to the ted spread pay on average higher risk-adjusted returns. Both findings are in accordance with the theory that relates margins and prices.
\end{abstract}

JEL classifications: G01, G12

Keywords: asset prices, margin requirements, capital constraint

*The authors thank Andrew Ang and Dennis Kristensen for valuable comments. The usual disclaimer applies.

${ }^{\dagger}$ Department of Economics, University of Sao Paulo. E-mail: bcg@usp.br

${ }^{\ddagger}$ Itau-BBA Bank. E-mail: Guilherme.Martins@itaubba.com 


\section{Introduction}

Some recent theoretical works show that margin requirements should impact asset prices in times of binding capital constraints (Brunnermeier and Pedersen 2009, Gromb and Vayanos 2010, Geanakoplos 2010, and Garleanu and Pedersen 2011, for example). The central mechanism of these models is a decrease in the demand of high-margin assets during periods when leveraged investors (investors who buy assets on margin) become capital constrained.

Garleanu and Pedersen (2011) discuss a striking implication of this fact: two assets with identical cash flows may not always have the same price. Such violations of the Law of One Price will occur when both (i) the margin requirements of the assets are different and (ii) the investors who buy assets on margin are capital constrained.

In the language of finance, this means that the risk premium of an asset is given by two components. The first is the usual product between risk factor(s) and loading(s). The second is what Garleanu and Pedersen (2011) call the "margin factor", a product between the margin requirement of the asset and a measure of how binding the capital constraint in the economy is.

The importance of this theoretical result goes beyond the pure understanding of asset prices. Some authors, such as Geanakoplos (2010) and Ashcraft, Garleanu, and Pedersen (2011), have been using these models to analyze the unconventional policies implemented by the Fed during the 2007-2010 financial crisis, when the size and com- 
position of the Fed's balance sheet changed dramatically. In January 2007, the Fed carried basically US Treasury bills. In the following three years, however, a variety of assets was included into the balance sheet in significant amounts. As Geanakoplos (2010) argues, the negative effect of margins on prices, together with the fact that these elements feed back on each other, could justify such a radical change in the Fed's policy.

In spite of the relevance of this discussion, there is still very little empirical evidence supporting the relation between margin requirements and asset prices. The theoretical papers mentioned above provide isolated examples for individual assets. For instance, Garleanu and Pedersen (2011) use the spread between corporate bonds and credit default swaps, and the covered interest rate parity to validate their model empirically. Ashcraft, Garleanu, and Pedersen (2011), in turn, show that when the Fed offered margins for some securities during the last financial crisis (through the Term Auction Facility - TAF - and the Term Securities Lending Facility - TSLF), the required rates of return on such securities decreased.

These are interesting empirical illustrations. However, if a margin factor does exist, this has economy-wide implications which should be tested. As we discuss below, in the time-series of aggregate returns, an aggregate margin factor (related to the margin requirement on the market portfolio) should be able to forecast future excess returns of the market portfolio. Moreover, in the cross-section of returns, stocks with higher exposures to the measure of capital constraint in the economy should pay higher average 
returns. This paper tests both implications and finds favorable empirical support for them.

We first construct an empirical counterpart of an aggregate margin factor and determine whether it can predict future returns of the S\&P 500 index. Relying on the theory of Garleanu and Pedersen (2011), the aggregate margin factor is computed by the product of the margin requirement for the $\mathrm{S} \& \mathrm{P} 500$ future index and the ted spread (which is a usual measure of how binding the capital contraint in the interbank market is). According to the results, during periods of binding capital constraint (high ted spread), a $1 \%$ increase in the margin requirement for the future contract of the S\&P 500 raises its expected excess return by at least $1.8 \%$ per year. Complementarily, during periods when the S\&P 500 margin is high, a $1 \%$ increase in the ted spread raises the expected excess return by at least $2.7 \%$ per year. These effects are controlled for other standard predictors of future returns such as earnings-price ratio, dividend-price ratio, dividend yield, market volatility, inflation and the relative bill rate.

Then, to test whether stocks with high exposures to the ted spread (controlled for other risk factors) pay higher average returns, we construct portfolios on the basis of such exposures (constant and time-varying), and estimate their alphas. Under all specifications, the portfolio with higher exposed stocks has a higher alpha. For instance, considering the portfolios sorted by time-varying loadings, the annualized alphas from the model including the 3 Fama-French factors equal $5.8 \%$ (for the high-exposure portfolio) and 2.3\% (for the low-exposure portfolio). Hence, a strategy of going short on 
the low-exposure portfolio and long on the high-exposure one generates a risk-adjusted excess return of $3.5 \%$ per year on average.

The rest of the paper is organized as follows. Section 2 provides a simple theoretical model that motivates the empirical work. Section 3 presents the empirical analysis. Section 4 concludes.

\section{The Theoretical Model}

In this section we present a theoretical model, based on Garleanu and Pedersen (2011), to motivate our empirical work. We summarize their model and refer the reader to their paper for a more detailed analysis, including how to solve for the general equilibrium.

The economy has two types of agents $n \in\{a, b\}$. Agent $a$ is the risk-averse type and $b$ is the brave one, with a smaller risk aversion, equal to one. Both agents have CRRA preferences and maximize

$$
E_{t} \int_{t}^{T}\left(e^{-\rho(s-t)} \frac{C_{s}^{1-\gamma^{n}}}{1-\gamma^{n}}\right) d s .
$$

There are several risky assets in the economy. The price of risky asset $i$ follows a Geometric Brownian Motion process

$$
d P_{t}^{i}=\mu_{t}^{i} P_{t}^{i} d t+P_{t}^{i} \sigma_{t}^{i} d w .
$$

In addition to the risky assets, there are two riskless money-market assets, both in zero net supply. While one asset represents borrowing and lending against collateral 
at the interest rate $r_{t}^{c}$, the other one is about uncollateralized loans with interest rate $r_{t}^{u}$

The first type is available to all agents in the economy. For example, when one investor takes a long position in a risky asset she can borrow in the collateralized loan market. To do so she must make some collateral available to her broker. The amount of required collateral is determined by the haircut applied by the broker. The haircut is the margin requirement, denoted by $m_{t}^{i}$, and determines how much of her own capital she must use to make the initial investment. Similarly, if she takes a short position, she must also deposit collateral as margin with her broker or at some exchange. In both cases, the margin is computed as a fraction of the total position: if the agent invests a fraction $\theta_{t}^{i}$ of her wealth $W_{t}$ in the risk asset $i$, she must deposit $m_{t}^{i}\left|\theta_{t}^{i}\right| W_{t}$ as margin. Note again that she must deposit a positive margin whether she is long or short in the asset. Finally, the margin deposits are remunerated at $r_{t}^{c}$.

The uncollateralized loan market is a standard one. It is riskless as is the collateralized loan. However, only type $b$ agent can contract uncollateralized loans. Therefore, as we see below, when this agent is capital constrained, the two interest rates are different.

At every instant, each consumer chooses how much to consume $\left(C_{t}\right)$, as well as the fraction of her wealth she wants to invest in the risky assets and in the uncollateralized loan market $\left(\eta_{t}^{u}\right)$. Any residual wealth is invested in the collateralized loan market. 
The evolution of wealth is then given by

$$
d W_{t}=\left[W_{t}\left(r_{t}^{c}+\eta_{t}^{u}\left(r_{t}^{u}-r_{t}^{c}\right)+\sum_{i} \theta_{t}^{i}\left(\mu_{t}^{i}-r_{t}^{c}\right)\right)-C_{t}\right] d t+W_{t} \sum_{i} \theta_{t}^{i} \sigma_{t}^{i} d w_{t}
$$

Consumers take as given all prices and maximize (1) subject to (2) and, because of the margin requirements, to

$$
\sum_{i} m_{t}^{i}\left|\theta_{t}^{i}\right|+\eta_{t}^{u} \leq 1
$$

as well.

The Hamilton-Jacobi-Bellman equation for the type $b$ consumer is then given by

$$
\underset{\theta_{t}^{i}, \eta_{t}^{u}}{\operatorname{Max}}\left\{r_{t}^{c}+\eta_{t}^{u}\left(r_{t}^{u}-r_{t}^{c}\right)+\sum_{i} \theta_{t}^{i}\left(\mu_{t}^{i}-r_{t}^{c}\right)-\frac{1}{2} \sum_{i, j} \theta_{t}^{i} \theta_{t}^{j} \sigma_{t}^{i} \sigma_{t}^{j}\right\},
$$

subject to $(3)$.

In the case agent $b$ is long in the risky asset $i$, the solution to this problem yields two conditions,

$$
\begin{gathered}
r_{t}^{u}-r_{t}^{c}=\psi_{t} \\
E_{t}\left(\frac{d P_{t}^{i}}{P_{t}^{i}}\right)-r_{t}^{c}=\gamma^{b} \beta_{t}^{i, C^{b}}+m_{t}^{i} \psi_{t}
\end{gathered}
$$

where $\psi_{t}$ is the shadow price of capital (i.e., the Lagrangian Multiplier associated with $(3))$, and $\beta_{t}^{i, C^{b}} \equiv \operatorname{cov}_{t}\left(\frac{d C_{t}^{b}}{C_{t}^{b}}, \frac{d P_{t}^{i}}{P_{t}^{i}}\right)$.

A similar problem is solved by the type $a$ agent. The only difference is that she cannot chose $\eta_{t}^{u}$. If we assume that her capital constraint is never biding, the solution to her portfolio choice problem is given by 


$$
E_{t}\left(\frac{d P_{t}^{i}}{P_{t}^{i}}\right)-r_{t}^{c}=\gamma^{a} \beta_{t}^{i, C^{a}}
$$

Then, by aggregating the Euler equations (Equations 5 and 6) across types $a$ and $b$, we end up with the equation for the risk premium of risky asset $i$,

$$
E_{t}\left(\frac{d P_{t}^{i}}{P_{t}^{i}}\right)-r_{t}^{c}=\gamma_{t} \beta_{t}^{i, C}+x_{t} m_{t}^{i} \psi_{t}
$$

where

$$
\gamma_{t}^{-1} \equiv \frac{1}{\gamma^{a}} \frac{C_{t}^{a}}{C_{t}}+\frac{1}{\gamma^{b}} \frac{C_{t}^{b}}{C_{t}}
$$

and

$$
x_{t} \equiv \frac{C_{t}^{b}}{\gamma^{b}}\left(\frac{C_{t}^{a}}{\gamma^{a}}+\frac{C_{t}^{b}}{\gamma^{b}}\right)^{-1} .
$$

Equation (7) is the main result of Garleanu and Pedersen's (2011) model. It states that the expected excess return of any risky asset is composed of two terms. The first term is the standard risk premium in the CAPM literature: the product of the price of risk, which is given by an average of the risk aversion of the different agents in the economy, and the covariance between aggregate consumption and the return on the asset. The second term, called margin factor, is the novelty. Because some investors might be capital constrained and cannot deposit additional margins, they require an additional premium to hold the asset in equilibrium.

The margin factor is a combination of three variables. First, $\psi_{t}$ is the shadow cost of buying on margin, and measures how binding the capital constraint is. According 
to Equation (4), it is given by the difference of two interest rates $r_{t}^{u}-r_{t}^{c}$. The second variable $\left(m_{t}^{i}\right)$ is the asset's margin requirement itself. The last variable $\left(x_{t}\right)$ gives the

importance of the constrained investor in the economy (that is, it defines the weight of the Euler equation of agent $b$ in the aggregate Euler equation). Hence, it determines the relevance of the margin factor in the aggregate economy. It is usually called the "risk-bearing capacity" of agent $b$. Even though the consumption share of the agent $b$ can be small, $x_{t}$ can still be large because it takes into account the difference in the risk aversion levels of types $a$ and $b$.

\section{Testable Implications of the Model}

Equation (7) has economy-wide implications for the time-series and the cross-section of expected returns, both of which are investigated in this section.

\subsection{Time-series Testable Implications}

Equation (7) is trivially related to the return on the market portfolio. Suppose that there are $S$ risky assets in the economy. Then, by aggregating (7) across assets $i=$ $1, \ldots, S$, we have

$$
E_{t}\left(\frac{d P_{t}}{P_{t}}\right)-r_{t}^{c}=\gamma_{t} \beta_{t}^{C}+x_{t} \psi_{t} m_{t}
$$

where 


$$
E_{t}\left(\frac{d P_{t}}{P_{t}}\right)-r_{t}^{c} \equiv \sum_{i=1}^{S}\left(E_{t}\left(\frac{d P_{t}^{i}}{P_{t}^{i}}\right)-r_{t}^{c}\right)
$$

is the expected excess return of the market portfolio,

$$
\beta_{t}^{C} \equiv \sum_{i=1}^{S} \beta_{t}^{i, C}
$$

is the covariance between aggregate consumption and the market portfolio return, and

$$
m_{t} \equiv \frac{1}{S} \sum_{i=1}^{S} m_{t}^{i}
$$

is the margin required to buy (on margin) the market portfolio, which is given by the average of the individual margin requirements.

There are three (related) testable direct consequences of Equation (10). First, (a) during periods of binding capital constraint (when $\psi_{t}$ is sufficiently high), the margin requirement on the market portfolio $\left(m_{t}\right)$ should forecast future returns. Second, (b) during periods of financial distress (when $m_{t}$ is sufficiently high), the measure of the relevance of the capital constraint $\left(\psi_{t}\right)$ should forecast future returns. Finally, (c) the effect of an increase in $\psi_{t}$ on future returns should depend on $m_{t}$ and vice-versa.

It is natural to test implications (a), (b), and (c) by estimating the regression

$$
r_{t+h}-r_{t+h}^{c}=\delta_{0}+\delta_{1} m_{t}+\delta_{2} \psi_{t}+\delta_{3} x_{t} m_{t} \psi_{t}+z_{t}^{\prime} \delta_{4}+e_{t+h}
$$

where $r_{t+h}$ and $r_{t+h}^{c}$ are the $h$-month ahead risky (S\&P 500) and collateralized risk-free 
returns respectively, $e_{t+h}$ is an error term with zero conditional mean, and $z_{t}$ is a $k \times 1$ vector with other standard predictors of future returns.

\subsubsection{Key Variables}

A main issue in the estimation of Equation (11) is data availability. First, as Geanakoplos (2010) points out, historical measures of margins are very hard to obtain. Second, it may not be immediately clear which variable should be used to represent $\psi_{t}$. Third, data on $x_{t}$, related to the ratio of the aggregate consumption due to the brave investor, is also not readily available.

With respect to the first issue, the Chicago Mercantile Exchange (CME) provides data on the margin requirements for the S\&P 500 future contract. If the brave agent can interchangeably trade spot and future contracts, and the spot and future markets are good substitutes, margin requirements in future and spot markets should be tightly, if not perfectly, related. Hence, under this assumption, we can use the CME margin requirements to construct $m_{t}$. Based on that, we compute the daily ratio between the initial margin requirements on S\&P 500 futures for members of the CME (available from April 1982) and the value of the underlying S\&P 500 index multiplied by the size of the contract. This is the usual way of computing margins. Then we use the end-of-month $m_{t} \cdot{ }^{1}$

With respect to $\psi_{t}$, the shadow price of capital, Equation (4) indicates that in

\footnotetext{
${ }^{1}$ Using the beginning-of-month series gives qualitatively the same results.
} 
equilibrium, $\psi_{t}$ has to be equal to the spread between the uncollateralized and the collateralized risk-free rates. In other words, it is a measure of how binding the capital constraint is. The well-known ted spread is given by the difference between the interest rates on interbank loans (Libor) and U.S. treasury bills and, because of that, it is a widely observed indicator of credit conditions in the interbank market. Hence, it is a natural choice to represent $\psi_{t}$. The ted spread is computed as the difference between the 3-month Libor rate and the 3-month treasury bill rate. For the Libor rate we use the Eurodollar 3-month deposit rate in the London market. Following the same convention as for margins, we use the end-of-month ted spread.

Regarding $x_{t}$, the problem of disaggregating consumption among different groups of individuals is not new in the asset pricing literature. Since Mankiw and Zeldes (1989), many papers have been trying to come up with measures for the consumption of stockholders as a way to address the equity premium puzzle. Because stockholders' consumption presents higher covariance with returns, such studies are able to generate more reasonable risk aversion levels. Ait-Sahalia, Parker, and Yogo (2004), for example, employ data on the consumption of luxury goods as a proxy for stockholder's consumption. More recently, Malloy, Moskowitz, and Vissing-Jørgensen (2009) use microlevel household consumption data to approximate this series.

We use the data of Malloy, Moskowitz, and Vissing-Jørgensen (2009), which is publicly available, to construct a proxy for $x_{t}$. By doing that, we are assuming that the ratio between the consumption of leveraged and nonleveraged agents vary closely with 
the ratio between the consumption of stockholders and nonstockholders. From Malloy, Moskowitz and Vissing-Jørgensen's (2009) consumption growth rates, we compute $x_{t}$ in accordance to equation (9). We impose $\gamma^{B}=1, \gamma^{A}=10$, and $x_{0}=27 \%$, which are the values employed by Garleanu and Pedersen (2011) in their analysis of the model's predictions. ${ }^{2}$ However, as we present below, the computed $x_{t}$ is almost constant in time (relative to $m_{t}$ and $\psi_{t}$ ). Hence, the presence of $x_{t}$ in the regressions will be immaterial to the results.

\subsubsection{Descriptive Statistics}

Our final data set consists of monthly observations for $m_{t}$ and $\psi_{t}$ from April 1982 to July 2011, and for $x_{t}$ from April 1982 to November 2004 (the consumption data of Malloy, Moskowitz and Vissing-Jørgensen (2009) ends in November 2004). The beginning of the sample (April 1982) is in accordance with the beginning of the CME margin requirements. Table I presents the descriptive statistics for $m_{t}, \psi_{t}$ and $x_{t}$.

[Table I about here]

The sample correlation between $m_{t}$ and $\psi_{t}$ is only $14 \%$. However, as Figure 1 illustrates, around periods of financial distress both series usually increase (although

\footnotetext{
${ }^{2}$ We tested a number of alternative values for such parameters and the results suffer no qualitative change at all.
} 
$m_{t}$ has a longer memory, i.e., it moves slower). Figure 1 also indicates that most part of the variation in the aggregate margin factor $m_{t} \psi_{t} x_{t}$ comes from the variables $m_{t}$ and $\psi_{t}$, given that $x_{t}$ is relatively constant.

[Figure 1 about here]

\subsubsection{Time-series Regressions}

We want to estimate Equation (11). However, our proxy for $x_{t}$ is only available until 2004. Fortunately $x_{t}$ can be excluded from our model with no harm, given that its contribution to the variation in $x_{t} m_{t} \psi_{t}$ is extremely small (as Figure 1 illustrates). To quantify this fact, we can compare the standard deviations of $\log \left(x_{t} m_{t} \psi_{t}\right)$ and $\log \left(m_{t} \psi_{t}\right) .{ }^{3}$ While the $\log$ of $x_{t} m_{t} \psi_{t}$ has a standard error of 0.835 , the standard error is 0.834 for the $\log$ of $m_{t} \psi_{t}$. To confirm the irrelevance of $x_{t}$, we estimated Equation (11), restricted to $1982-2004$, with and without $x_{t}$. Unreported results show that the parameters estimates are qualitatively the same under both specifications.

Given that, the model we estimate to test implications (a), (b), and (c) defined above is

$$
r_{t+h}-r_{t+h}^{c}=\delta_{0}+\delta_{1} m_{t}+\delta_{2} \psi_{t}+\delta_{3} m_{t} \psi_{t}+z_{t}^{\prime} \delta_{4}+e_{t+h}
$$

\footnotetext{
${ }^{3}$ Comparing the standard deviations without taking logs would be misleading since $x_{t}$ is always below 1 and this would depress the variance of $x_{t} m_{t} \psi_{t}$ per se.
} 
We include in $z_{t}$ some prominent variables explored in the predictability literature, one at a time. These are the earnings-price ratio, the dividend-price ratio, the dividend yield, the market volatility, inflation and the relative bill rate. These variables are defined and computed as follows.

The earnings-price ration (e-p) is the log of earnings (12-month moving sum of earnings on the S\&P 500 index) minus the log of prices (S\&P 500 index). The dividendprice ratio $(\mathrm{d}-\mathrm{p})$ is the difference between the log of dividends (12-month moving sums of dividends paid on the S\&P 500 index) and the log of prices. The dividend yield $(\mathrm{d}-\mathrm{y})$ is the difference between the log of dividends and the log of 12-month lagged prices. The market volatility (vol) is the monthly average of squared daily returns on the $\mathrm{S} \& \mathrm{P} 500$. Inflation (inf) is the $\mathrm{CPI}$ inflation. The relative bill rate (rrel) is difference between the 3-month treasury bill return and its 12-month moving average. Data on earnings, dividends and returns are from Robert Shiller's website ${ }^{4}$. Inflation and t-bill returns are taken from the Federal Reserve Bank of St. Louis dataset.

Table II presents the estimation results of Equation (12) for 12-, 18-, 24-, and 48month ahead excess returns respectively. ${ }^{5}$ The table is divided into 4 blocks, one for each horizon. Each block reports the coefficients of the margin requirements $\left(\delta_{1}\right)$, of the ted spread $\left(\delta_{2}\right)$, and of the product between the margin and the ted spread $\left(\delta_{3}\right)$,

\footnotetext{
${ }^{4}$ http://www.econ.yale.edu/ $\sim$ shiller/data.htm, as in March 2012.

${ }^{5}$ Equation (12) was estimated using annualized returns in \%. The margin and the ted spread (also annualized) were expressed in $\%$ as well.
} 
along with their standard errors, column by column. Moreover, each block is divided into seven rows. In the first row, no control is added to the regression. Then, from the second to the seventh row, the results are controlled individually for the indicated variables. The coefficients related to the control variables are not reported. The last two columns (7 and 8) of the table present the marginal effects of the ted spread and of the margin requirement on future returns, respectively, $\delta_{2}+\delta_{3} m$ and $\delta_{1}+\delta_{3} \psi$.

\section{[Table II about here]}

According to Table II, the predictability results appear at about the 24-month horizon. This is justified by the behavior of $m_{t} \psi_{t}$, as illustrated in Figure 2. The series spikes around periods of financial distress and, once it spikes, it takes from 1.5 to 2 years to return to its low level. This characteristic, compatible with the idea of relatively brief periods of binding capital constraint and financial distress, is what produces higher returns about 24 months after a spike in $m_{t} \psi_{t}$ (prices decrease when $m_{t} \psi_{t}$ spikes, and return about 24 months later). Note that, according to Table II, the predictability power becomes weak at the 48-month horizon. This indicates that the predictability at the 24-month horizon is not an artificial result given by the well-known combination of overlapping returns with persistent regressors (if this were the case, the predictability power would increase with the horizon).

Our main goal in the time-series analysis is to estimate the marginal effects of $m_{t}$ and $\psi_{t}$ on future returns, conditional on high levels of $m_{t}$ and $\psi_{t}$ (as Equation (10) indicates, 
when either $m_{t}$ or $\psi_{t}$ are low the margin factor loses importance). Accordingly, columns 7 and 8 of Table II report the partial derivatives of Equation (12) with respect to the margin and the ted spread evaluated at $\psi=2.5 \%$ and $m=10 \%$. The average values for these variables are $0.7 \%$ and $4.7 \%$, respectively, and the maximum values are $5.1 \%$ and $13.5 \%$ (see Table I). Therefore, $\psi=2.5 \%$ represents periods when the capital constraint is restrictive. In turn, $m=10 \%$ represents periods when margins are high.

The computations, using the 24-month horizon estimates in Table II, indicate that, departing from $\psi=2.5 \%$ and $m=10 \%$, an additional $1 \%$ in the margin requirement (ted spread) should depress stock prices by $2.3 \%(6.9 \%)$ on average per year. These are the average marginal effects across specifications (across the rows in the third block). The lowest marginal effect of margin is $1.8 \%$ (when controlled for inf or rrel) and the lowest marginal effect of the ted spread is $2.7 \%$ (when controlled for d-p).

These results are strictly favorable to the time-series implications (a), (b), and (c) defined above. First, as the marginal effect estimates indicate, both $m_{t}$ and $\psi_{t}$ positively forecast future returns, conditional on high levels of $m_{t}$ and $\psi_{t}$ (implications $\mathrm{a}$ and $\mathrm{b})$. Second, as the significance of the product $m_{t} \psi_{t}$ confirms, the effect of one variable does depend on the level of the other (implication c).

In the next sub-section, we investigate the cross-sectional implication of the model. 


\subsection{Cross-sectional Testable Implications}

The most direct way of testing the cross-sectional implication of Equation (7) would be by comparing the relation between risk-adjusted returns and margin requirements across different assets (if the model is correct, assets with higher margin requirements should pay higher risk-adjusted returns in periods of capital contraint). Unfortunately, given the difficulty in obtaining data on margin requirements for individual stocks, tests of this kind are restricted to isolated and individualized examples such as the ones in Garleanu and Pedersen (2011).

However, it is still possible to promote an interesting evaluation of Equation (7) using cross-sectional data on the stock market, even with no data on individual margin requirements. This can be done by splitting the cross-sectional implication of Equation (7) into two complementary parts. First, the model predicts that stocks with higher exposure to $\psi_{t}$ (controlled for other risk factors) should pay higher returns on average. Second, it says that a stock's exposure to $\psi_{t}$ is determined by its margin requirement. Both parts are necessary conditions for the model to be valid. Together, they are sufficient. Given that information on individual stock margin requirements is not publicly available, we are not able to empirically address the second prediction. Nevertheless, we can test the first one.

Accordingly, in this sub-section, we investigate whether stocks with higher exposure to $\psi_{t}$ (controlled for other risk factors) pay higher returns on average. As we will see, we 
find strong favorable evidence in this direction. Since this is only a necessary condition for the model to be valid, our favorable results do not provide a conclusive crosssectional test for the model (empirical results that are in line to a necessary condition cannot be conclusive). However, the theoretical relation between the exposure to $\psi_{t}$ and average returns, when controlled for other risk factors, is not a trivial one (i.e., it is not directly predicted by any other theory). Moreover, such a relation has never been documented empirically to the best of our knowledge. Given that, we see the

following results as relevant empirical evidence in favor of Garleanu and Pedersen's (2011) model.

It is important to mention that using individual stock data to test the model in the cross-section makes sense only if margin requirements vary across stocks. By analyzing private data from a large hedge fund, Ang, Gorovyy and Inwegen (2011) report that this is indeed the case. According to their Table 1, margin requirements do vary widely across securities, ranging from $5 \%$ to $50 \%$.

\subsubsection{Constructing Portfolios using Constant Margin-betas}

We call the exposure of an asset return to $\psi_{t}$ the "margin-beta". We first assume a constant margin-beta, given by $\beta_{i}$. Using the reasoning of the model, this initial restriction makes sense if individual margin requirements do not vary much over time (we later relax this assumption). 
We construct portfolios on the basis of stocks' margin-betas. Controlling for other risk factors, in December of each year we estimate a pre-ranking $\beta_{i}$ for every NYSE, AMEX and NASDAQ stock with share code 10 and 11 in the CRSP (Center for Research in Security Prices of the University of Chicago) database, using five years of prior monthly returns. ${ }^{6}$ That is, in each December, for each security, we estimate

$$
r_{i, t}^{e}=\beta_{F, i}^{\prime} F_{t}+\beta_{i} \psi_{t}+e_{t}
$$

where $r_{i, t}^{e}$ is the excess return of security $i$ and the vector $F_{t}$ contains a constant, the 3 Fama-French factors, and a momentum factor (all these factors are from Kenneth French web-site ${ }^{7}$.

We then form ten equally weighted portfolios based on $\beta_{i}$ and compute their returns for the next twelve months. We repeat this process for each year from 1987 to 2009 . The result is monthly returns on ten portfolios sorted on margin-betas from January 1988 to December 2010.

Figure 3 reports the relation between the post-ranking margin-betas of the ten portfolios and their average returns. The post-ranking betas are obtained by estimating regression (13) over the whole sample period (January 1988 to December 2010).

\footnotetext{
${ }^{6}$ Stocks that do not have information for the last 5 years are not included in the portfolios for the following year. The average number of remaining stocks (permno) in each December is 3180 (ranging from 2507 to 3461$)$.

${ }^{7}$ http://mba.tuck.dartmouth.edu/pages/faculty/ken.french/data_library.html, as in March 2012.
} 
[Figure 3 about here]

The y-axis of Figure 3 presents the portfolios' annualized average returns. There is a positive relation between margin-betas and average returns. ${ }^{8}$ This is a first favorable empirical evidence of the validity of the model. However, returns on the y-axis are not controlled for other risk-factors.

To investigate whether the margin-beta is priced in the presence of other risk factors, we compute the portfolios alphas for the ten portfolios. The CAPM alpha is computed with respect to risk factor related to the market excess return (MKT) and the 3-factor alpha with respect to all three Fama-French factors (MKT, SMB, HML). That is,

$$
\begin{aligned}
& r_{i, t}^{e}=\alpha_{i, C A P M}+\beta_{i, M K T} M K T_{t}+e_{1, t} \\
& r_{i, t}^{e}=\alpha_{i, 3 F}+\beta_{i, M K T} M K T_{t}+\beta_{i, S M B} S M B_{t}+\beta_{i, H M L} H M L_{t}+e_{2, t} .
\end{aligned}
$$

Table III presents the alphas and their t-statistics. We multiply the alphas by 12 to interpret them in terms of annualized returns. Portfolio number 1 has the stocks with low margin-betas and portfolio number 10 has the stocks with high margin-betas. Therefore, if the margin-beta risk is priced, the premium for this risk should be positive, in that alphas should increase with portfolio number.

[Table III about here]

\footnotetext{
${ }^{8}$ The relation has a p-value equal to 0.012 .
} 
The evidence in Table III favors the pricing of the constant margin-beta. Both the CAPM and the 3-factor alphas of the tenth portfolio are considerably higher than those of the first portfolio. A "10 minus 1" spread, which goes long on portfolio 10 and short on portfolio 1 would have a CAPM alpha of $2.6 \%$ and a 3 -factor alpha of $2.8 \%$ (these are simply the differences between the alphas from portfolios 10 and 1). In other words, the strategy of shorting portfolio 1 and longing portfolio 10 provides a risk-adjusted excess return of $2.8 \%$ per year on average. We test the hypothesis that all ten alphas are jointly equal to zero, using the test of Gibbons, Ross, and Shanken (1989). For all three models, the hypothesis is rejected at a $1 \%$ significance level.

\subsubsection{Constructing Portfolios using Time-varying Margin-betas}

We now relax the assumption of a constant exposure to the ted spread. To do that, the margin-beta is assumed to be given by

$$
\beta_{i, t}=\beta_{0, i}+\beta_{1, i} m_{t}
$$

where $m_{t}$ is the margin requirement for the market portfolio used in the previous sub-section.

This approach to incorporating time-variation in betas was first proposed by Shanken (1990) and has been used frequently (see, for instance, Pastor and Stambaugh 2003). It is helpful whenever the researcher has a good idea on what may be causing the time-variation on the factor exposure. This seems to be the case here, given that a 
stock's exposure to $\psi_{t}$ should be determined by its margin requirement. Based on that, Equation (14) does possess some appeal ex ante. First, the constant will be capturing the stable component of the individual margin as before. Second, the margin requirement on the market portfolio will account for a common time-variation in individual margins given by, for example, an aggregate tail risk. Note that the loading on the aggregate margin $\left(\beta_{1, i}\right)$ can vary across stocks.

In each December, for each security, we then estimate

$$
r_{i, t}^{e}=\beta_{F, i}^{\prime} F_{t}+\left(\beta_{0, i}+\beta_{1, i} m_{t}\right) \psi_{t}+e_{t},
$$

and form ten equally weighted portfolios based on the predicted margin-betas, that is,

$$
\widehat{\beta}_{0, i}+\widehat{\beta}_{1, i} m_{D e c}
$$

where $m_{D e c}$ is the aggregate margin requirement in the respective December. As before, we then compute the portfolios' returns for the next twelve months and repeat this process for each year from 1987 to 2010 . The result is monthly returns on ten portfolios, now sorted by time-varying margin-betas.

By estimating regression (15) over the whole sample period we can then compute the post-ranking average time-varying margin-betas as

$$
\frac{1}{T} \sum_{t=1}^{T}\left(\widehat{\beta}_{0, i}+\widehat{\beta}_{1, i} m_{t}\right) .
$$


Figure 4 presents a significant positive relation between the post-ranking average time-varying margin-betas of the portfolios and their average returns. ${ }^{9}$ Such a relation is stronger under time-varying than under constant betas.

[Figure 4 about here]

The better fit of time-varying betas is confirmed by the analysis of the alphas. Table IV presents strong results in favor of the theoretical model. The alphas of the three "10 minus 1" spreads are now even higher: the CAPM alpha is now $3.4 \%$ and the 3-factor alpha is 3.5\% and the test of Gibbons, Ross, and Shanken (1989) rejects the null hypothesis of all alphas equal to zero at a $1 \%$ significance level.

[Table IV about here]

\section{Conclusion}

This study provides favorable evidence for the existence of an aggregate margin factor in the economy. Based on the theory of Garleanu and Pedersen (2011), we define four testable implications of the existence of such a factor. Three of them are related to the predictability of future returns on the market portfolio. The forth is about the cross-section of stock returns.

\footnotetext{
${ }^{9}$ The relation has a p-value equal to 0.0001 .
} 
According to our time-series results, (i) during periods of binding capital constraint in the interbank market (periods of high ted spread), the margin requirement on the S\&P 500 future contract can predict returns on the S\&P 500, (ii) during periods of high margin requirement on the $\mathrm{S} \& \mathrm{P} 500$ future contract, the measure of the relevance of the capital constraint (the ted spread) can predict returns on the S\&P 500, and (iii) the effect of an increase in the ted spread on future returns does depend on the margin requirement, and vice-versa. In turn, according to our cross-sectional analysis, stocks with higher exposures to the ted spread, controlled for the exposures to other standard risk factors, pay higher risk-adjusted returns on average. All these results are in line with Garleanu and Pedersen's (2011) theory.

The importance of the existence of a margin factor goes beyond the pure understanding of asset prices. For instance, some authors, such as Geanakoplos (2010) and Ashcraft, Garleanu, and Pedersen (2011), have been using this argument to justify the unconventional policies implemented by the Fed during the 2007-2010 financial crisis (when the size and composition of the Fed's balance sheet changed dramatically). 


\section{REFERENCES}

Ait-Sahalia, Y., Parker, J., and Yogo, M. (2004). Luxury Goods and the Equity Premium, Journal of Finance 59, 2959-3004.

Ang, A., Gorovyy, S., and Inwegen, G. (2011). Hedge Fund Leverage, Journal of Financial Economics, forthcoming.

Ashcraft, A., Garleanu, N., and Pedersen, L. (2011). Two Monetary Tools: Interest Rates and Haircuts, NBER Macroeconomics Annual, forthcoming.

Brunnermeier, M., and Pedersen, L. (2009). Market Liquidity and Funding Liquidity, Review of Financial Studies 22, 2201-2238.

Garleanu, N., and Pedersen, L. (2011). Margin-Based Asset Pricing and Deviations from the Law of One Price, Review of Financial Studies, forthcoming.

Geanakoplos, J. (2010). The Leverage Cycle, Cowles Foundation Discussion Paper, $1715 \mathrm{R}$.

Goyal, A., and Welch, I. (2007). A Comprehensive Look at the Empirical Performance of Equity Premium Prediction, Review of Financial Studies 21, 1455-1508.

Gromb, D., and Vayanos, D. (2010). Financially Constrained Arbitrage and CrossMarket Contagion, working paper. 
Malloy, C., Moskowitz, T., and Vissing-Jørgensen, A. (2009). Long-Run Stockholder Consumption Risk, Journal of Finance 64, 2427-2479.

Mankiw, G., and Zeldes, S. (1991). The Consumption of Stockholders and Nonstockholders, Journal of Financial Economics 29, 97-112.

Parker, J. (2001). The Consumption Risk of the Stock Market, Brookings Papers on Economic Activity 2, 279-333

Parker, J., and Vissing-Jørgensen, A. (2009). Who Bears Aggregate Fluctuations and How?, American Economic Review: Papers 83 Proceedings 99, 399-405.

Pastor, L., and Stambaugh, R. (2003). Liquidity Risk and Expected Stock Returns, Journal of Political Economy 111, 642-685.

Shanken, J. (1990). Intertemporal Asset Pricing: An Empirical Investigation, Journal of Econometrics 45, 99-120. 


\section{Figures}

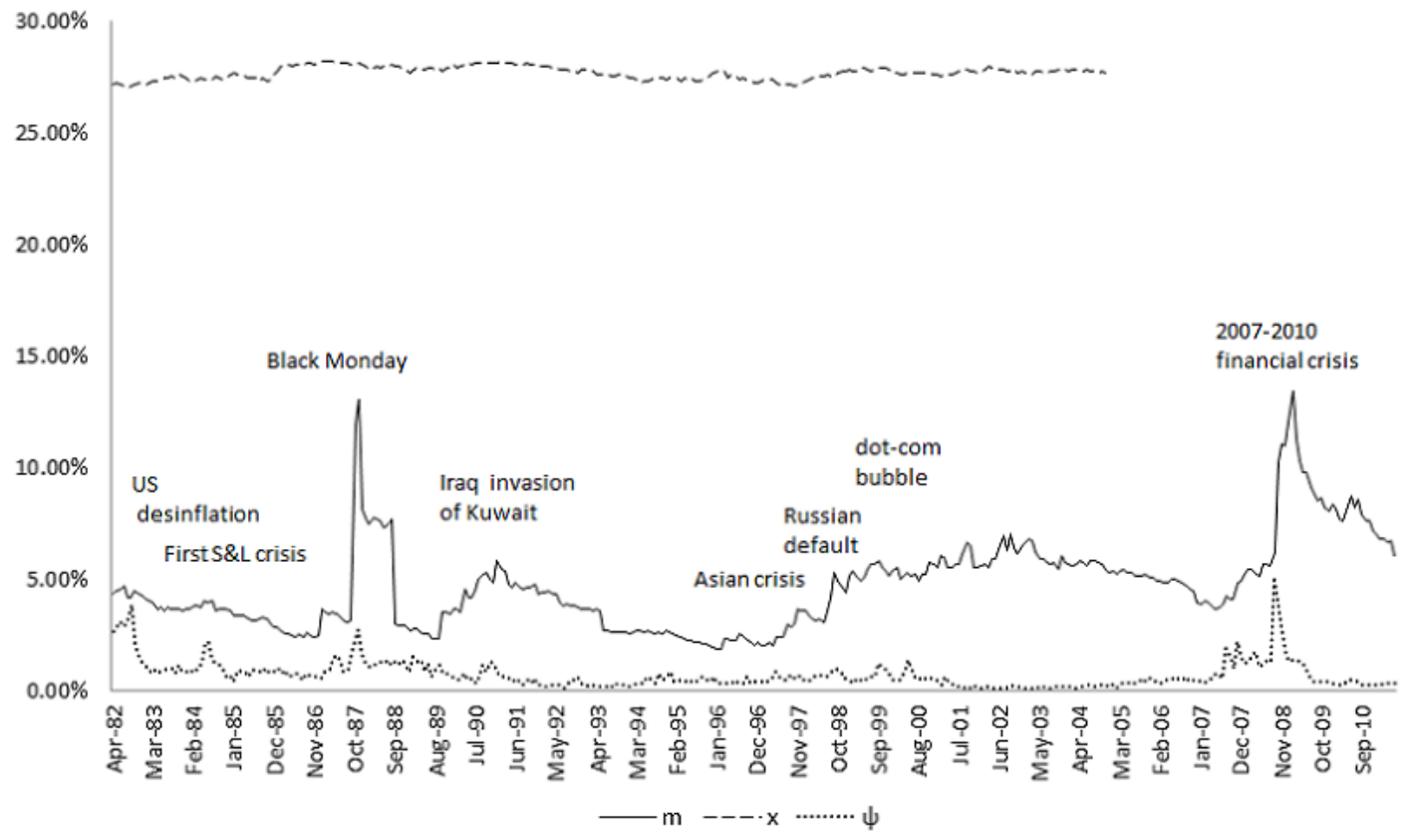

This figure presents the evolution of the three components of the aggregate margin factor, defined as $m_{t} \psi_{t} x_{t}$. The first component, $m_{t}$ (solid line), is the margin requirement of the S\&P 500 future. It is computed as the ratio between the initial margin requirements on the S\&P 500 future for members of the Chicago Mercantile Exchange and the value of the underlying S\&P 500 index multiplied by the size of the contract. The second component, $\psi_{\text {: }}$ (dotted line), is the ted spread, given by the difference between the 3-month Libor rate and the 3-month treasury bill rate. The third component, $x_{\mathrm{t}}$ (dashed line), is the risk-bearing capacity of the leveraged agent, defined as in Equation (9). It is computed using the consumption data of stockholders and nonstockholders from Malloy, Moskowitz, and Vissing-Jorgensen (2009), imposing $\gamma^{a}=10$ and $\gamma^{b}=1$ (the same values used by Garleanu and Pedersen 2011). The series for $x_{t}$ ends in November 2004, which is the end of the consumption data from Malloy, Moskowitz, and Vissing-Jorgensen (2009).

Figure 1: The three components of the aggregate margin factor. 


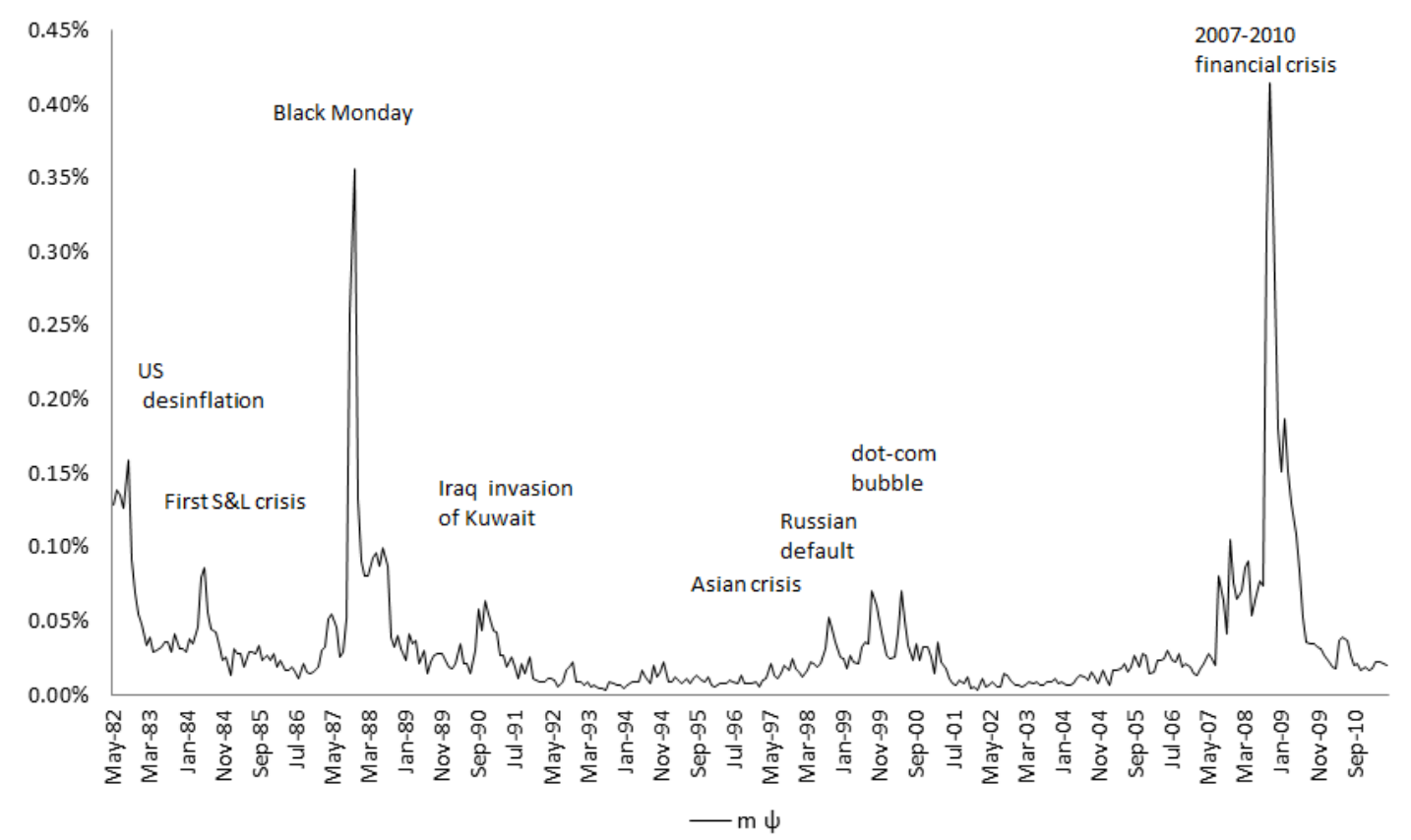

The figure presents the evolution of the product $m_{t} \psi_{t}$, where $m_{t}$ is the margin requirement of the S\&P 500 future, and $\psi_{t}$ is the ted spread. The series for $m_{t}$ is computed as the ratio between the initial margin requirements on the S\&P 500 future for members of the Chicago Mercantile Exchange and the value of the underlying S\&P 500 index multiplied by the size of the contract. The series for $\psi_{t}$ is given by the difference between the 3-month Libor rate and the 3-month treasury bill rate.

Figure 2: The product of the margin requirement for the S\&P 500 future contract and the ted spread. 


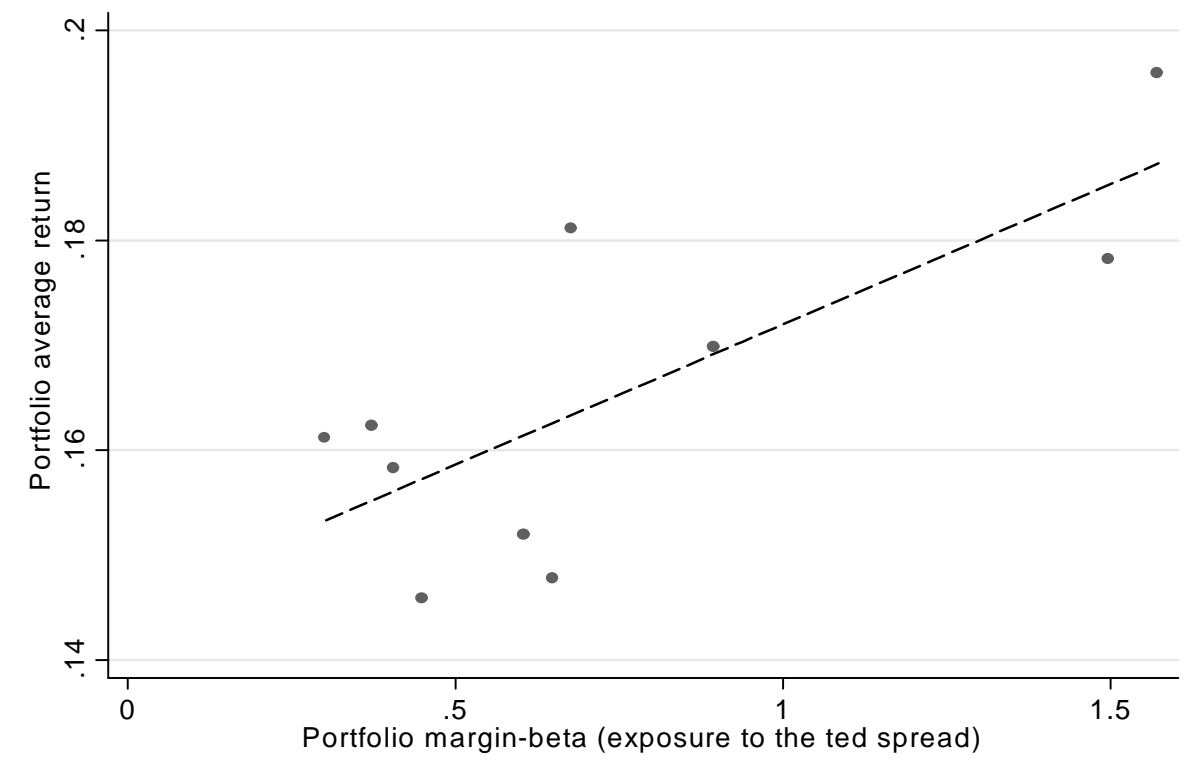

The figure reports the relation between the post-ranking exposures to the ted spread of the ten portfolios and the portfolios average returns. We call the exposure of an asset return to the ted spread by margin-beta. The portfolios are constructed on the basis of stocks' marginbetas. Controlling for other risk factors (Fama-French 3 factors and momentum), in December of each year we estimate a pre-ranking margin-beta for every NYSE, AMEX and NASDAQ stock with share code 10 and 11 in the CRSP database, using five years of prior monthly returns. We then form ten equally weighted portfolios based on the margin-betas and compute their returns for the next twelve months. We repeat this process for each year from 1987 to 2009. The result is monthly returns on ten portfolios sorted on margin-betas from January 1988 to December 2010. Stocks that do not have information for the last 5 years are not included in the portfolios for the following year.

Figure 3: Cross-sectional analysis of portfolios average returns vs. portfolios margin-betas. 


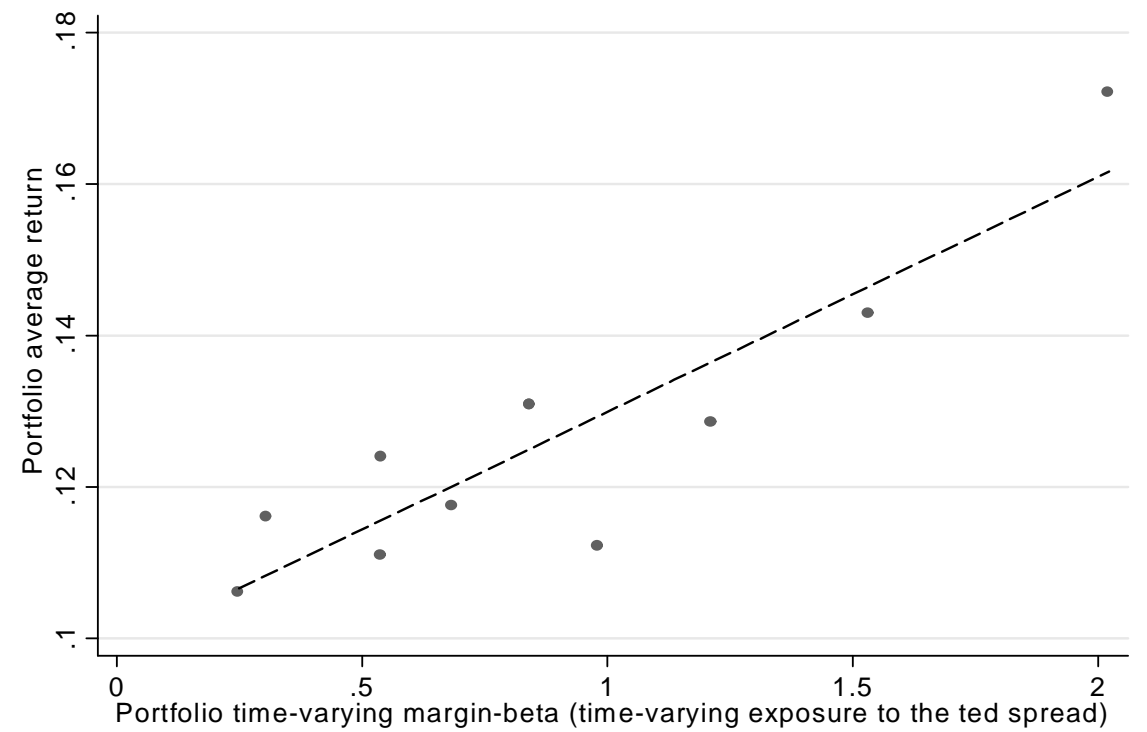

The figure reports the relation between the average of the post-ranking time-varying exposures to the ted spread of the ten portfolios and the portfolios average returns. We call the exposure of an asset return to the ted spread by margin-beta. The portfolios are constructed on the basis of stocks' time-varying margin-betas. Controlling for other risk factors (Fama-French 3 factors and momentum), in December of each year we estimate a preranking time-varying margin-beta for every NYSE, AMEX and NASDAQ stock with share code 10 and 11 in the CRSP database, using five years of prior monthly returns. Time-varying marginbetas are given by equation 13 . The stocks are sorted into ten equally weighted portfolios by first estimating equation 14 and then computing the stocks margin-betas in each December according to equation 15 . We then compute the portfolios returns for the next twelve months. We repeat this process for each yearfrom 1987 to 2009. The result is monthly returns on ten portfolios sorted on time-varying margin-betas from January 1988 to December 2010. Stocks that do not have information for the last 5 years are not included in the portfolios for the following year.

Figure 4: Cross-sectional analysis of portfolios average returns vs. portfolios

time-varying margin-betas. 


\section{Tables}

\begin{tabular}{cccccccc} 
& $\begin{array}{c}(1) \\
\text { mean }\end{array}$ & $\begin{array}{c}(2) \\
\text { min. }\end{array}$ & $\begin{array}{c}(3) \\
\text { max. }\end{array}$ & $\begin{array}{c}(4) \\
\text { std. dev. }\end{array}$ & $\begin{array}{c}(5) \\
\text { correl. } m_{\mathrm{t}}\end{array}$ & $\begin{array}{c}(6) \\
\text { correl. } \psi_{\mathrm{t}}\end{array}$ & $\begin{array}{c}(7) \\
\text { correl. } x_{\mathrm{t}}\end{array}$ \\
\hline$m_{\mathrm{t}}$ & $4.7 \%$ & $1.9 \%$ & $13.5 \%$ & $2.0 \%$ & $100 \%$ & & \\
$\psi_{\mathrm{t}}$ & $0.7 \%$ & $0.1 \%$ & $5.1 \%$ & $0.6 \%$ & $14 \%$ & $100 \%$ & \\
& & & & & & & \\
$x_{\mathrm{t}}$ & $27.7 \%$ & $27.0 \%$ & $28.3 \%$ & $0.3 \%$ & $35 \%$ & $-15 \%$ & $100 \%$ \\
\hline
\end{tabular}

This table presents the descriptive statistics of the three variables contained in the aggregate margin factor: $m_{t}$ is the margin requirement of S\&P 500 future, $\psi_{t}$ is the ted spread (the difference between the 3-month Libor rate and the 3-month treasury bill rate), and $x_{t}$ is the risk-bearing capacity of the leveraged agent (defined as in Equation 9 and computed using consumption data of stockholders and nonstockholders, from Malloy, Moskowitz, and Vissing-Jørgensen 2009, imposing $\gamma^{0}=10$ and $\gamma^{b}=1$, the same values used by Garleanu and Pedersen 2011). The first column is the sample mean. The second column is the sample minimum value. The third column is the sample maximum value. The fourth column is the sample standard deviation. Columns 5 to 7 present the correlation matrix.

Table I: Descriptive statistics of the variables in the aggregate margin factor. 


\begin{tabular}{|c|c|c|c|c|c|c|c|c|c|}
\hline & \multicolumn{6}{|c|}{ estimated parameters from equation (11) } & \multicolumn{2}{|c|}{ marginal effects } \\
\hline & & $\delta_{1}$ & $\sigma\left(\delta_{1}\right)$ & $\delta_{2}$ & $\sigma\left(\delta_{2}\right)$ & $\delta_{3}$ & $\sigma\left(\delta_{3}\right)$ & $\delta_{1}+\delta_{3} \psi$ & $\delta_{2}+\delta_{3} \mathrm{~m}$ \\
\hline & & (1) & (2) & (3) & (4) & (5) & (6) & (7) & (8) \\
\hline \multirow{7}{*}{ 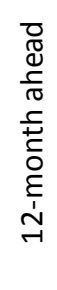 } & no control & -1.529 & $(1.872)$ & -6.190 & $(10.23)$ & 1.185 & (1.137) & & \\
\hline & $e-p$ & -0.248 & (1.967) & -10.07 & (10.25) & 1.104 & (1.173) & & \\
\hline & $d-p$ & -0.643 & (1.688) & -12.13 & (9.786) & 1.194 & (1.108) & & \\
\hline & $d-y$ & 0.0350 & (1.639) & -11.06 & (10.19) & 1.225 & (1.165) & & \\
\hline & vol & -1.622 & (1.863) & -7.964 & (10.02) & 1.652 & (1.231) & & \\
\hline & inf & -1.345 & (1.862) & -4.537 & (9.553) & 0.895 & (1.069) & & \\
\hline & rrel & -1.362 & (1.789) & -5.126 & (9.910) & 1.106 & (1.124) & & \\
\hline \multirow{7}{*}{ 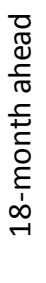 } & no control & -2.100 & (1.938) & -9.112 & (7.177) & $1.622 *$ & $(0.952)$ & $2.1 \%$ & $7.1 \%$ \\
\hline & $e-p$ & -1.153 & (1.932) & -12.18 & (7.523) & 1.579 & (0.991) & $2.8 \%$ & $3.6 \%$ \\
\hline & $d-p$ & -1.134 & (1.773) & $-14.54^{* *}$ & (6.850) & $1.574^{*}$ & (0.917) & $2.8 \%$ & $1.2 \%$ \\
\hline & $d-y$ & -0.330 & (1.848) & $-13.07^{*}$ & (7.208) & 1.515 & $(0.966)$ & & \\
\hline & vol & -2.200 & (1.925) & -10.86 & (7.272) & $2.081 *$ & (1.113) & $3.0 \%$ & $10.0 \%$ \\
\hline & $\inf$ & -2.030 & (1.954) & -8.546 & (7.052) & 1.521 & (0.955) & & \\
\hline & rrel & -1.972 & $(1.920)$ & -8.371 & (7.111) & $1.561^{*}$ & $(0.945)$ & $1.9 \%$ & $7.2 \%$ \\
\hline \multirow{7}{*}{ 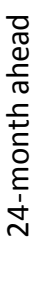 } & no control & -2.804 & (1.952) & $-9.500 *$ & (5.365) & $1.835^{* *}$ & $(0.866)$ & $1.8 \%$ & $8.9 \%$ \\
\hline & $e-p$ & -1.927 & (1.913) & $-14.68^{* *}$ & (5.690) & $1.978^{* *}$ & $(0.898)$ & $3.0 \%$ & $5.1 \%$ \\
\hline & $d-p$ & -1.617 & (1.964) & $-13.93 * * *$ & (5.110) & $1.660 *$ & $(0.876)$ & $2.5 \%$ & $2.7 \%$ \\
\hline & $d-y$ & -0.855 & (2.168) & $-12.31^{* *}$ & (5.548) & $1.574 *$ & (0.937) & $3.1 \%$ & $3.4 \%$ \\
\hline & vol & -2.845 & (1.944) & $-10.32^{*}$ & (5.715) & $2.052^{* *}$ & (1.014) & $2.3 \%$ & $10.2 \%$ \\
\hline & inf & -2.819 & (1.955) & $-9.600 *$ & (5.447) & $1.853 * *$ & $(0.890)$ & $1.8 \%$ & $8.9 \%$ \\
\hline & rrel & -2.823 & (1.992) & $-9.604 *$ & (5.329) & $1.844^{* *}$ & $(0.875)$ & $1.8 \%$ & $8.8 \%$ \\
\hline \multirow{7}{*}{$\begin{array}{l}\bar{\nabla} \\
\frac{\Phi}{\Phi} \\
\frac{\Phi}{\sigma}\end{array}$} & no control & $-3.454^{* *}$ & (1.564) & -5.381 & $(4.907)$ & 1.461* & $(0.819)$ & $0.2 \%$ & $9.2 \%$ \\
\hline & $e-p$ & -2.642 & (1.731) & -9.384 & (6.191) & 1.405 & (0.901) & & \\
\hline & $d-p$ & -1.869 & (1.758) & $-9.577^{* *}$ & (4.782) & 1.054 & $(0.858)$ & & \\
\hline & $d-y$ & -1.460 & (1.992) & -7.298 & (5.382) & 0.880 & (0.974) & & \\
\hline & vol & $-3.446^{* *}$ & (1.547) & -5.486 & (5.197) & 1.488 & (0.937) & & \\
\hline & $\inf$ & $-3.465 * *$ & (1.576) & -5.538 & (5.019) & $1.475 *$ & (0.834) & $0.2 \%$ & $9.2 \%$ \\
\hline & rrel & $-3.653^{* *}$ & (1.571) & -6.484 & (4.432) & $1.610 * *$ & $(0.775)$ & $0.4 \%$ & $9.6 \%$ \\
\hline
\end{tabular}

Notes: Blocks 1 to 4 report results from monthly predictive regressions of S\&P 500 excess returns over 12-, 18-, 24- and 48-month horizons, respectively, for the period between April 1982 to June 2011 (equation 11). Each block reports the coefficients and standard errors of the S\&P 500 futures margin requirements (columns 1 and 2), of the ted spread (columns 3 and 4), and of the product between the margin and the ted spread (columns 5 and 6). Rows of each block report the estimates described above from regressions controlled for the following variables, respectively: earnings-price ratio (e-p), dividend-price ratio $(d-p)$, dividend yield (d-y), monthly average of the daily squared returns of the S\&P 500 (vol), CPI inflation (inf) and relative bill rate (rrel). Such variables are computed according to Goyal and Welch (2008) (rrel is in accordance to Lettau and Ludvigson 2001). Columns 7 and 8 report the marginal effects of a $1 \%$ increase in the margin (fixing the ted spread at $2.5 \%$ ) and of a $1 \%$ increase in the ted spread (fixing the margin at $10 \%$ ) on future returns. Standard errors are computed by Newey-West with lag length equal to the horizon. Significance levels are indicated as follows: ${ }^{*} \mathrm{p}<.10 ;{ }^{* *} \mathrm{p}<.05 ;{ }^{* * *} \mathrm{p}<.01$.

Table II: Predictive regressions (equation 12) 


\begin{tabular}{|c|c|c|c|c|c|c|c|c|c|c|}
\hline & \multicolumn{10}{|c|}{ Portfolios } \\
\hline & 1 & 2 & 3 & 4 & 5 & 6 & 7 & 8 & 9 & 10 \\
\hline CAPM alpha & $\begin{array}{c}4.5 \% \\
(1.25)\end{array}$ & $\begin{array}{c}5.2 \% \\
(2.30)\end{array}$ & $\begin{array}{c}5.4 \% \\
(2.63)\end{array}$ & $\begin{array}{c}6.0 \% \\
(3.19)\end{array}$ & $\begin{array}{c}4.6 \% \\
(2.53)\end{array}$ & $\begin{array}{c}4.2 \% \\
(2.01)\end{array}$ & $\begin{array}{c}4.6 \% \\
(2.17)\end{array}$ & $\begin{array}{c}7.0 \% \\
(2.78)\end{array}$ & $\begin{array}{c}6.0 \% \\
(1.94)\end{array}$ & $\begin{array}{c}7.1 \% \\
(1.54)\end{array}$ \\
\hline 3-factor alpha & $\begin{array}{c}2.1 \% \\
(0.95)\end{array}$ & $\begin{array}{c}2.5 \% \\
(1.95)\end{array}$ & $\begin{array}{c}2.7 \% \\
(2.50)\end{array}$ & $\begin{array}{c}3.4 \% \\
(2.80)\end{array}$ & $\begin{array}{c}2.3 \% \\
(1.99)\end{array}$ & $\begin{array}{c}1.4 \% \\
(1.12)\end{array}$ & $\begin{array}{c}2.0 \% \\
(1.55)\end{array}$ & $\begin{array}{c}4.3 \% \\
(2.83)\end{array}$ & $\begin{array}{c}3.5 \% \\
(1.70)\end{array}$ & $\begin{array}{c}5.0 \% \\
(1.58)\end{array}$ \\
\hline
\end{tabular}

The table reports the alphas of ten portfolios formed according to their exposures to the ted spread. We call the exposure of an asset return to the ted spread the margin-beta. The portfolios are constructed on the basis of stocks' margin-betas. Controlling for other risk factors (Fama-French 3 factors and momentum), in December of each year we estimate a pre-ranking margin-beta for every NYSE, AMEX and NASDAQ stock with share code 10 and 11 in the CRSP database, using five years of prior monthly returns. We then form ten equally weighted portfolios based on the margin-betas and compute their returns for the next twelve months. We repeat this process for each year from 1987 to 2009 . The result is monthly returns on ten portfolios sorted on margin-betas from January 1988 to December 2010. Stocks that do not have information for the last 5 years are not included in the portfolios for the following year. The ten portfolios' post-ranking alphas, in percent per year, are estimated as intercepts from the regressions of excess portfolio post-ranking returns on excess market returns (CAPM alpha) and on the Fama-French factor returns (3-factor alpha). The t-statistics are in parentheses.

Table III: Alphas of ten portfolios formed according to the stocks' margin-betas (i.e.,

their exposures to the ted spread). 


\begin{tabular}{|c|c|c|c|c|c|c|c|c|c|c|}
\hline & \multicolumn{10}{|c|}{ Portfolios } \\
\hline & 1 & 2 & 3 & 4 & 5 & 6 & 7 & 8 & 9 & 10 \\
\hline CAPM alpha & $\begin{array}{c}4.6 \% \\
(1.28)\end{array}$ & $\begin{array}{c}5.5 \% \\
(2.35)\end{array}$ & $\begin{array}{c}5.2 \% \\
(2.49)\end{array}$ & $\begin{array}{c}4.3 \% \\
(2.30)\end{array}$ & $\begin{array}{c}4.8 \% \\
(2.70)\end{array}$ & $\begin{array}{c}5.4 \% \\
(2.82)\end{array}$ & $\begin{array}{c}4.5 \% \\
(2.07)\end{array}$ & $\begin{array}{c}5.6 \% \\
(2.28)\end{array}$ & $\begin{array}{c}6.6 \% \\
(2.12)\end{array}$ & $\begin{array}{c}8.0 \% \\
(1.77)\end{array}$ \\
\hline 3-factor alpha & $\begin{array}{c}2.3 \% \\
(1.09)\end{array}$ & $\begin{array}{c}2.7 \% \\
(2.05)\end{array}$ & $\begin{array}{c}2.6 \% \\
(2.09)\end{array}$ & $\begin{array}{c}1.7 \% \\
(1.68)\end{array}$ & $\begin{array}{c}2.6 \% \\
(2.50)\end{array}$ & $\begin{array}{c}2.9 \% \\
(2.48)\end{array}$ & $\begin{array}{c}1.8 \% \\
(1.33)\end{array}$ & $\begin{array}{c}2.9 \% \\
(1.90)\end{array}$ & $\begin{array}{c}4.2 \% \\
(2.05)\end{array}$ & $\begin{array}{c}5.8 \% \\
(1.75)\end{array}$ \\
\hline
\end{tabular}

The table reports the alphas of ten portfolios formed according to their time-varying exposures to the ted spread. We call the exposure of an asset return to the ted spread the margin-beta. The portfolios are constructed on the basis of stocks time-varying margin-betas. Controlling for other risk factors (Fama-French 3 factors and momentum), in December of each year we estimate a pre-ranking time-varying margin-beta for every NYSE, AMEX and NASDAQ stock with share code 10 and 11 in the CRSP database, using five years of prior monthly returns. Time-varying margin-betas are given by equation 13 . The stocks are sorted into ten equally weighted portfolios by first estimating equation 14 and then computing the stocks margin-betas in each December according to equation 15. We then compute the portfolios' returns for the next twelve months. We repeat this process for each year from 1987 to 2009. The result is monthly returns on ten portfolios sorted on time-varying margin-betas from January 1988 to December 2010. Stocks that do not have information for the last 5 years are not included in the portfolios for the following year. The ten portfolios post-ranking alphas, in percent per year, are estimated as intercepts from the regressions of the excess portfolios post-ranking returns on excess market returns (CAPM alpha) and on the Fama-French factor returns (3-factor alpha). The t-statistics are in parentheses.

Table IV: Alphas of ten portfolios formed according to the stocks' time-varying margin-beta (i.e., the stocks' time-varying exposures to the ted spread). 